\title{
ALGORITMA K-MEANS UNTUK MENDETEKSI FRAME PADA VIDEO ASLI DAN VIDEO TAMPERING
}

\author{
Dewi Yunita Sari ${ }^{1}$ \\ ${ }^{1}$ Teknik Komputer, Fakultas Teknik, Universitas Wiralodra \\ 1dewiyunita245@gmail.com
}

\begin{abstract}
ABSTRAK
Sebuah video tersusun dari frame dalam jumlah yang banyak, Apabila terdapat frame-frame yang menunjukkan ketidakwajaran maka dapat disimpulkan bahwa file rekaman video tersebut telah mengalami tampering. Video yang telah mengalami tampering mengalami perubahan dari bentuk aslinya berupa penambahan atau perubahan video. Banyaknya kasus pemasalahan video asli yang di manipulasi menjadi video tampering maka peneliti mendeteksi keaslian video tersebut dengan menggunakan Algoritma K-Means. Fitur yang digunakan dalam penelitian ini adalah beberapa rangkaian frame dari sebuah video kemudian di proses dengan menampilkan clustering atau kelompok data Red Green Blue. Untuk menentukan centroid awal digunakan cara yaitu diambil nilai pixel dari Red Green Blue. Hasil yang dicapai antara frame video asli dan frame video tampering mempunyai nilai yang berbeda yaitu frame 4 pada video asli dengan jumlah pixel yang lebih sedikit dibanding dengan jumlah pixel pada video tampering.
\end{abstract}

Kata Kunci: Video; Tampering; Frame; Algoritma K-Means

\begin{abstract}
A video is composed of a large number of frames. If there are frames that show irregularities, it can be concluded that the video recording file has experienced tampering. Videos that have undergone tampering have changed from their original form in the form of additions or changes to videos. The number of cases of original video problems that were manipulated into video tampering, the researchers detected the authenticity of the video using the K-Means Algorithm. The feature used in this research is a series of frames from a video which is then processed by displaying the Red Green Blue clustering or data group. To determine the initial centroid, the method used is to take the pixel value from Red Green Blue. The results achieved between the original video frame and the tampering video frame have a different value, namely frame 4 in the original video with a smaller number of pixels than the number of pixels in the tampering video.
\end{abstract}

Keyword: Video; Tampering; Frame; Algoritma K-Means

\section{PENDAHULUAN}

Suatu rekaman video pada hakikatnya merupakan susunan frame dalam jumlah yang banyak yang menyusun rekaman video yang berisikan objek-objek yang bergerak (moving object). Semakin tinggi nilai frame per detik (fps) dan tingkat resolusinya maka rekaman video tersebut akan memiliki kualitas yang semakin baik dan jelas untuk dilihat. Hal ini dikarenakan gambar moving objek-nya tidak patah-patah dan bersifat normal (alamiah) [1]. Sebuah video tersusun dari frame dalam jumlah yang banyak, sehingga frame-frame tersebut selanjutnya dapat dianalisis untuk melihat tampering yang terjadi pada video tersebut. 
Apabila terdapat frame-frame yang menunjukkan ketidakwajaran maka dapat disimpulkan bahwa file rekaman video tersebut telah mengalami tampering.

Video tampering berasal dari video asli yang di manupulasi oleh seseorang dengan menggunakan software tertentu. Video tampering merupakan suatu proses menyisipkan obyek tertentu ke dalam sebuah video, obyek yang disisipikan dapat berupa rangkaian atau potongan frame dari video yang sama atau berbeda[2] atau Menurut [3] menyisipkan potongan sejumlah frame tertentu pada sejumlah frame yang lain.

Video yang telah mengalami Tampering mengalami perubahan dari bentuk aslinya berupa penambahan atau perubahan gambar atau video. Perubahan tersebut dapat diklasifikasikan sebagai tindakan sengaja atau tidak sengaja. Tampering yang disengaja memiliki tujuan yang jahat dengan memodifikasikan konten atau menghapus hak cipta. Disamping itu, tampering yang tidak disengaja merupakan konsekuensi dari dari proses operasional digital, seperti memperbaiki kecerahan, perubahan format, pengurangan ukuran, dll. Pada signal video teknik tampering dapat diklasifikasikan sebagai perubahan spasial dan temporal. Teknik tampering spasial disesuaikan dengan perubahan yang dibuat berdasarkan pixel pada frame [5].

Menurut [6] Video sangat penting karena menjadi sumber utama informasi, oleh karena itu dilakukan pendeteksian video. Berikut ini beberapa contoh kasus manipulasi video yaitu Beberapa tindakan manipulasi video yang dihapus dari beberapa frame, sehingga kejadian yang fakta dapat disembunyikan. Misalnya, seorang memotong beberapa frame dari video dalam permainan sepak bola, yang bertujuan untuk menyembunyikan pelanggaran dalam permainan tersebut. Sebuah video pengamatan dirusak dengan menghapus beberapa frame pada kasus kriminal. Peristiwa-peristiwa tersebut sangat penting untuk dianalisis dalam forensik frame [4].

Berdasarkan dengan review, peneliti [5] telah melakukan penelitian deteksi video dengan pendekatan pada frame video dari berbagai gambar dengan hasil yaitu menunjukkan letak frame pada video yang telah dihapus dan menunjukkan lokasi pada video yang telah mengalami penyisipan, dibandingkan dengan penelitian ini adalah mendeteksi video dengan metode localization tampering pada frame dan histogram untuk menunjukkan letak atau lokasi yang terjadi tampering, peneliti [7] juga telah melakukan penelitian deteksi video berdasarkan fitur gambar dengan metode lokalisasi dengan menemukan hasil yang tepat dimana video diduplikasi, dibandingkan dengan penelitian ini adalah mendeteksi video dengan metode localization tampering pada frame dan histogram untuk menunjukkan letak atau lokasi yang terjadi tampering, dan peneliti [8] telah melakukan penelitian deteksi video dengan membandingkan antar frame video, dengan hasil yaitu mengetahui letak pada frame video yang telah mengalami tampering, dibandingkan dengan penelitian ini adalah mendeteksi video dengan metode localization tampering pada frame dan histogram untuk menunjukkan letak atau lokasi yang terjadi tampering.

Banyaknya video asli yang di manipulasi oleh seseorang dengan menggunakan software tertentu maka peneliti mendeteksi keaslian frame pada video tersebut dengan menggunakan algoritma K-Means.

\section{METODE PENELITIAN}

Pada tahapan ini Algoritma K-Means yang digunakan untuk mengidentifikasi video asli atau video tampering.

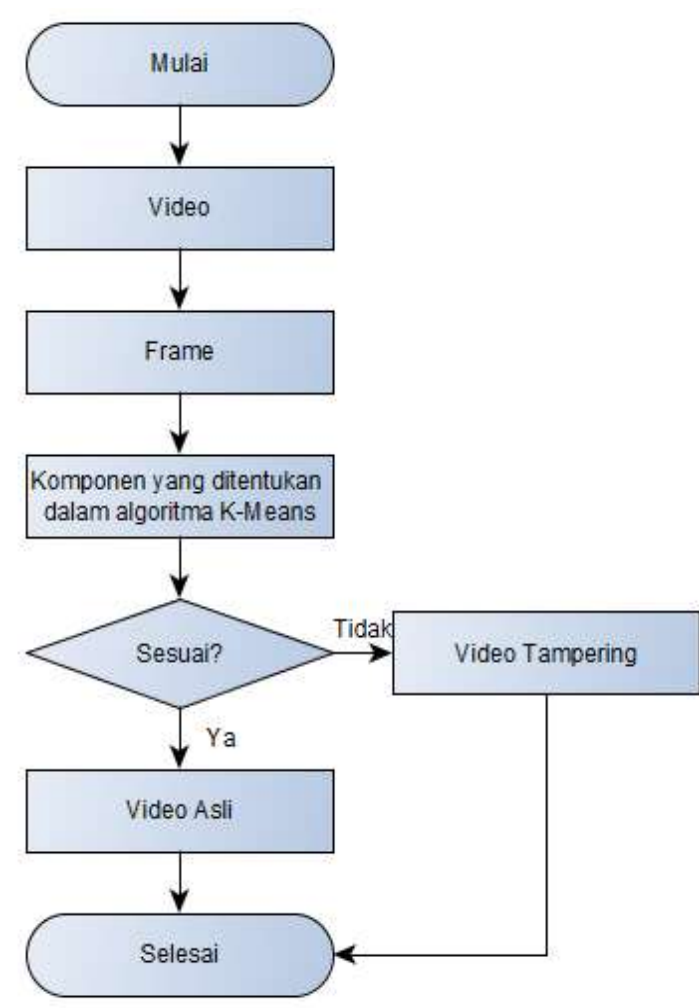

Gambar 1. Flowchart deteksi video tampering 
Pada tahap Pre-processing ini akan dilakukan ekstraksi frame pada file rekaman video, yaitu dengan mengubah file rekaman video ke dalam bentuk frame agar dapat disusun sebagai citra digital yang berurutan. Gambar berikut adalah diagram alir dari ekstraksi sebuah file rekaman video yaitu:

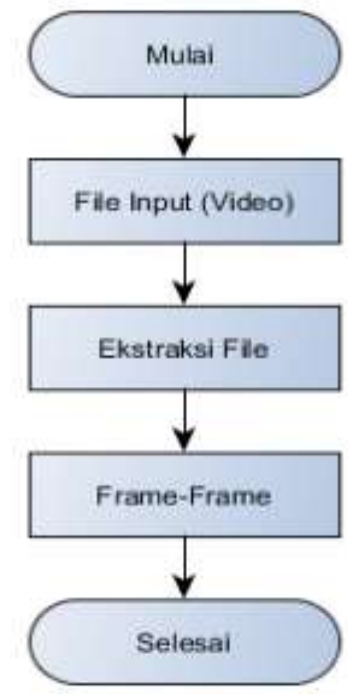

Gambar 2. Diagram pre-processing

Dari file rekaman video di ekstraksi menjadi beberapa frame, dari beberapa frame tersebut akan dideteksi dengan menggunakan algoritma K-Means. Berikut informasi tentang video yang akan dianalisis

Tabel 1. Informasi Mengenai Rekaman Video Asli

\begin{tabular}{|l|l|}
\hline Parameter & Satuan \\
\hline Format & Movie Clip \\
\hline File Size & $79.5 \mathrm{MB}$ \\
\hline Duration & 1 menit 40 detik $=100 \mathrm{~s}$ \\
\hline Overall Bit Rate & $9356 \mathrm{kbps}$ \\
\hline Format Video & MPG \\
\hline Width & 720 pixels \\
\hline Height & 576 pixels \\
\hline Frame Rate & 25 Frame/second \\
\hline Bit rate & $256 \mathrm{kbps}$ \\
\hline
\end{tabular}

Tabel 2. Informasi Mengenai Rekaman Video Tampering

\begin{tabular}{|l|l|}
\hline Parameter & Satuan \\
\hline Format & $\begin{array}{l}\text { Windows Media audio/Video } \\
\text { File }(. w m v)\end{array}$ \\
\hline File Size & $74.0 \mathrm{MB}$ \\
\hline Duration & 1 menit 40 detik $=100 \mathrm{~s}$ \\
\hline Overall Bit Rate & $6320 \mathrm{kbps}$ \\
\hline Format Video & WMV \\
\hline Width & 1280 pixels \\
\hline
\end{tabular}

\begin{tabular}{|l|l|}
\hline Height & 720 pixels \\
\hline Frame Rate & 25 Frame/second \\
\hline Bit rate & $320 \mathrm{kbps}$ \\
\hline
\end{tabular}

Analisis video dengan menggunakan algoritma K-Means ini menggunakan fitur frame dalam penentuan clustering. Rumus algoritma K-Means adalah:

$$
\begin{aligned}
D_{L 1}\left(x_{2}, x_{1}\right) & =\left|x_{2}-x_{1}\right|_{1} \\
& =\sqrt{\sum_{j=1}^{p}\left(x_{2 j}-x_{1 j}\right)^{2}}
\end{aligned}
$$

Langkah analisis ini maka harus ada pembanding antara video, maka dilakukan attack dengan cara zooming, cropping, rotation, grayscale, dari attack tersebut maka dapat membedakan antara file rekaman video tampering dan file video asli dengan menganalisis setiap frame by frame, perhitungan matrik pada histogram frame

\section{PEMBAHASAN}

Hasil ekstraksi pada video asli dan video tampering dilakukan analisis pada nilai pixel warna dengan menggunakan algoritma $K$-means, yaitu dengan menampilkan clustering atau kelompok data RGB.

Secara umum algoritma dasar dari $K$ Means Clustering adalah dengan menentukan $\mathrm{K}$ sebagai jumlah cluster yang dibentuk. Dalam menentukan banyaknya cluster $\mathrm{K}$ dilakukan dengan beberapa pertimbangan seperti pertimbangan teoritis dan konseptual yang mungkin diusulkan untuk menentukan berapa banyak cluster. Claster $\mathrm{K}$ di tentukan dari beberapa frame berikut:

Tabel 3. Analisis Nilai Pixel Warna

\begin{tabular}{|c|c|c|c|c|c|c|}
\hline \multirow{2}{*}{ Frame } & \multicolumn{3}{|c|}{ Video Asli } & \multicolumn{3}{c|}{ Video Tampering } \\
\cline { 2 - 7 } & $\mathrm{R}$ & $\mathrm{G}$ & $\mathrm{B}$ & $\mathrm{R}$ & $\mathrm{G}$ & $\mathrm{B}$ \\
\hline 1 & 198 & 186 & 212 & 227 & 221 & 245 \\
\hline 2 & 198 & 186 & 210 & 227 & 221 & 245 \\
\hline 3 & 199 & 187 & 211 & 228 & 220 & 245 \\
\hline 4 & 200 & 193 & 212 & 192 & 192 & 192 \\
\hline 5 & 203 & 192 & 210 & 196 & 196 & 196 \\
\hline 6 & 216 & 206 & 221 & 199 & 199 & 199 \\
\hline 7 & 204 & 199 & 217 & 198 & 198 & 198 \\
\hline 8 & 225 & 211 & 233 & 212 & 212 & 212 \\
\hline 9 & 224 & 213 & 234 & 207 & 207 & 207 \\
\hline 10 & 224 & 210 & 231 & 220 & 220 & 22 \\
\hline
\end{tabular}

digunakan cara yaitu diambil nilai pixel dari

RGB. Kemudian dari setiap nilai pixel diambil 
nilai tengahnya, digunakan rumus sebagai berikut:

$$
\mathrm{v}=\frac{\sum_{i=1}^{n} \mathrm{xi}}{\mathrm{n}}
$$

Tabel 4. Perhitungan Controid Awal Pada Video Asli Dan Video Tampering

\begin{tabular}{|c|c|c|c|c|c|c|}
\hline \multirow{2}{*}{$\begin{array}{c}\text { Fram } \\
\mathrm{e}\end{array}$} & \multicolumn{3}{|c|}{ Asli } & \multicolumn{3}{c|}{ Tempering } \\
\cline { 2 - 7 } & $\mathrm{R}$ & $\mathrm{G}$ & $\mathrm{B}$ & $\mathrm{R}$ & $\mathrm{G}$ & $\mathrm{B}$ \\
\hline 1 & 99 & 93 & 106 & 113,5 & 110,5 & 122,5 \\
\hline 2 & 99 & 93 & 105 & 113,5 & 110,5 & 122,5 \\
\hline 3 & 99,5 & 93,5 & 105,5 & 114 & 110 & 122,5 \\
\hline 4 & 100 & 96,5 & 106 & 96 & 96 & 96 \\
\hline 5 & 101,5 & 96 & 105 & 98 & 98 & 98 \\
\hline 6 & 108 & 103 & 110,5 & 99,5 & 99,5 & 99,5 \\
\hline 7 & 102 & 99,5 & 108,5 & 99 & 99 & 99 \\
\hline 8 & 112,5 & 105,5 & 116,5 & 106 & 106 & 106 \\
\hline 9 & 112 & 106,5 & 117 & 103,5 & 103,5 & 103,5 \\
\hline 10 & 112 & 105 & 115,5 & 110 & 110 & 110 \\
\hline
\end{tabular}

Frame 4 dari video asli yang memiliki citra 8x8 dengan derajat keabuan 4 sampai 20 (ada 12 buah derajat keabuan), dengan matrik sebagai berikut:
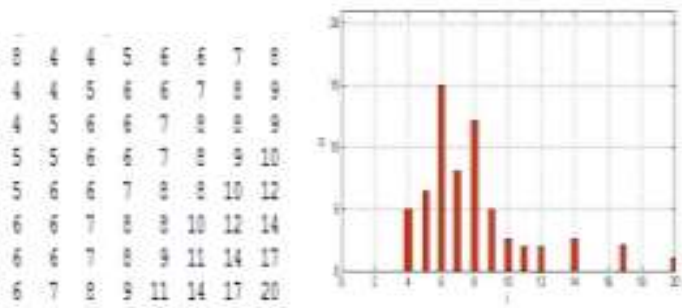

Gambar 3. Matrik Dan Grafik Pada Video Asli

Untuk mendapatkan dari citra diatas pertama-tama kita harus menghitung jumlah kemunculan masing-masing dari grey-level, ni, dimana $i$ adalah nilai grey-level yaitu:

Tabel 5. Perhitungan Controid Awal Pada Video Asli

\begin{tabular}{|l|c|c|l|c|c|}
\hline $\boldsymbol{i}$ & $\boldsymbol{n i}$ & $\boldsymbol{h i = n i / n ( n = 6 4 )}$ & $\boldsymbol{i}$ & $\boldsymbol{n i}$ & $\boldsymbol{h i = n i / n ( n = 6 4 )}$ \\
\hline 4 & 5 & 0,078 & 10 & 3 & 0,047 \\
\hline 5 & 6 & 0,094 & 11 & 2 & 0,031 \\
\hline 6 & 15 & 0,234 & 12 & 2 & 0,031 \\
\hline 7 & 8 & 0,125 & 14 & 3 & 0,047 \\
\hline 8 & 12 & 0,187 & 17 & 2 & 0,031 \\
\hline 9 & 5 & 0,078 & 20 & 1 & 0,016 \\
\hline
\end{tabular}

Tabel 2. merupakan tabel matrik dari salah satu frame pada video asli, yang mana angka tersebut akan digunakan untuk menghitung. Hasil perhitungan matrik selanjunya dibandingkan dengan perhitungan matrik pada video tampering. Frame 4 dari video tampering yang memiliki citra $8 \times 8$ dengan derajat keabuan 4 sampai 48 (ada 32 buah derajat keabuan), dengan matrik sebagai berikut:
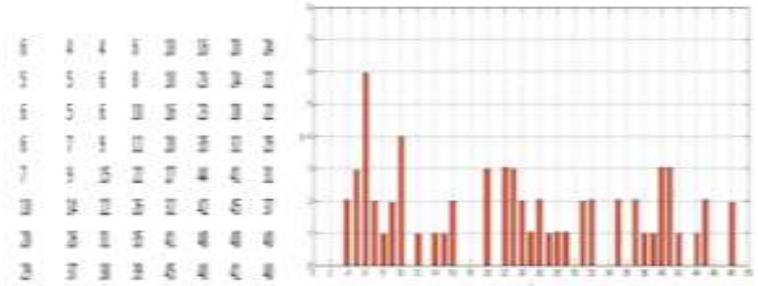

Gambar 4. Matrik Dan Grafik Pada Video Tampering

Hasil perhitungan Gambar 4. pada frame 4 dari video tampering sebagai berikut:

Tabel 6. Perhitungan Controid Awal Pada Video Tampering

\begin{tabular}{|c|c|c|c|c|c|}
\hline $\boldsymbol{i}$ & $\boldsymbol{n i}$ & $\boldsymbol{h i = n i / n}(\boldsymbol{n}=\mathbf{6 4})$ & $\boldsymbol{i}$ & $\boldsymbol{n i}$ & $\boldsymbol{h i = n i / n}(\boldsymbol{n}=\mathbf{6 4})$ \\
\hline 4 & 2 & 0,031 & 26 & 2 & 0,031 \\
\hline 5 & 3 & 0,047 & 27 & 1 & 0,016 \\
\hline 6 & 6 & 0,094 & 28 & 1 & 0,016 \\
\hline 7 & 2 & 0,031 & 29 & 1 & 0,016 \\
\hline 8 & 1 & 0,016 & 31 & 2 & 0,031 \\
\hline 9 & 2 & 0,031 & 32 & 2 & 0,031 \\
\hline 10 & 4 & 0,062 & 35 & 2 & 0,031 \\
\hline 12 & 1 & 0,016 & 37 & 2 & 0,031 \\
\hline 14 & 1 & 0,016 & 38 & 1 & 0,016 \\
\hline 15 & 1 & 0,016 & 39 & 1 & 0,016 \\
\hline 16 & 2 & 0,031 & 40 & 3 & 0,047 \\
\hline 20 & 3 & 0,047 & 41 & 3 & 0,047 \\
\hline 22 & 3 & 0,047 & 42 & 1 & 0,016 \\
\hline 23 & 3 & 0,047 & 44 & 1 & 0,016 \\
\hline 24 & 2 & 0,031 & 45 & 2 & 0,031 \\
\hline 25 & 1 & 0,016 & 48 & 2 & 0,031 \\
\hline
\end{tabular}

Dari hasil perhitungan matrik histogram secara matematika antara frame video asli dan frame video tampering mempunyai nilai yang berbeda yaitu frame 4 pada video asli dengan jumlah pixel yang lebih sedikit dibanding dengan jumlah pixel pada video tampering sehingga histogram pada video tampering lebih besar dari pada video asli, hal tersebut maka menunjukkan terjadi tampering pada frame ke 4 pada video tampering.

\section{KESIMPULAN}

Setelah melakukan beberapa hal terkait dengan deteksi dan analisis dari video asli dan video tampering dengan Algoritma K-Means maka diperoleh beberapa kesimpulan berikut ini:

1. Konsep dasar dalam mendeteksi video ini yang pertama yang dilakukan adalah tahap Pre-processing, tahap ini dilakukan dengan ekstraksi frame pada file rekaman video, yaitu dengan mengubah file rekaman video 
ke dalam bentuk frame-frame agar dapat dianalisis frame.

2. Hal yang harus dilakukan untuk mengidentifikasi terjadinya tampering dengan menggunakan algoritma $K$-Means yaitu dengan menganalisis pada nilai pixel warna dengan menampilkan clustering atau kelompok data RGB, kemudian dilakukan analisis dengan Algoritma K-Means dengan mengubah file rekaman video ke dalam bentuk frame-frame agar dapat disusun sebagai citra digital yang berurutan selanjutnya dianalisis frame. Dari hasil perhitungan matrik histogram secara matematika antara frame video asli dan frame video tampering mempunyai nilai yang berbeda yaitu frame 4 pada video asli dengan jumlah pixel yang lebih sedikit dibanding dengan jumlah pixel pada video tampering sehingga histogram pada video tampering lebih besar dari pada video asli, hal tersebut maka menunjukkan terjadi tampering pada frame ke 4 pada video tampering.

\section{DAFTAR PUSTAKA}

[1] M. N. Al-azhar, Digital Forensic: Panduan Praktis Investigasi Komputer. Jakarta, 2012.

[2] E. Signal and P. Conference, "Milani, Fontani, 2012, An overview on video forensics.pdf," no. Eusipco, pp. 1229-1233, 2012.

[3] P. Bestagini, S. Milani, M. Tagliasacchi, and S. Tubaro, "Local tampering detection in video sequences," 2013 IEEE Int. Work. Multimed. Signal Process. MMSP 2013, pp. 488-493, 2013.

[4] C. Feng, Z. Xu, S. Jia, W. Zhang, and Y. Xu, "Motion-Adaptive Frame Deletion Detection for Digital Video Forensics," IEEE Trans. Circuits Syst. Video Technol., vol. 27, no. 12, pp. 2543-2554, 2016.

[5] A. Gironi, A. Piva, and S. It, "A VIDEO FORENSIC TECHNIQUE FOR DETECTING FRAME DELETION AND INSERTION Dept . of Information Engineering, Universit 'a di Firenze , Firenze ( IT ) CNIT , Universit `Dept . of Electronic and Telecommunications , Politecnico di Torino , Torino ( IT ) Dept," pp. 6267-6271, 2014.

[6] R. C. Pandey, S. K. Singh, and K. K. Shukla, "Passive copy-move forgery detection in videos," Proc. - 5th IEEE Int. Conf. Comput. Commun. Technol. ICCCT 2014, pp. 301306, 2014.

[7] S. Mathai, M., \& Emmanuel, "Video Forgery Detection and Localization Using Normalized Cross-Correlation of Moment Features," pp. 149-152, 2016.

[8] B. E. Koenig, D. S. Lacey, and G. B. Richards, "Video frame comparisons in digital video authenticity analyses," $J$. Forensic Identif., vol. 62, no. 2, pp. 165182, 2012. 